3.

\title{
Krebs des Stirnbeins und einiger Gesichtsknochen als Folge traumatischer Beschädigung.
}

\author{
Von Dr. J. Minkiewicz aus Witebsk.
}

(Hierzu Taf. VI.)

Ein Grusier, ein Mann ron mittlerer Constitution, 40 Jahre alt, erhielt im Monat Mai des Jahres 1858 während einer Schlägerei einen heftigen Stoss mit einem beschlogenen Stiefel auf die Mitte des unteren Theils des Stirnbeines. Seit dieser Zeit entwickelte sich zwischen den Augenbrauen, an der Stelle, wo der Kranke den Schlag bekommen hatte, allmälig eine schmerzende Geschwulst. Vom Monat December an wuchs die Geschwulst bedeutend schneller. Bis zu Anfang des Monats Februar 1859 war sie här, von dieser Zeit an erweichte dieselbe in der Mitte der obernäche und es konnte eine deutliche Schwappung constatint werden, Zu gleicher Zeit schwanden die Kräfte des Kranken; er wurde mager und es gesellte sich daza ein hektisches Fieber mit schwachen abendlichen Paroxysmen. - Der Kranke wendete sich an einen einheimischen Charlatan, der ibm die Geschwulst an zwei Stellen, wo sie am meisten hervortrat, durchsclinitt. Am 27. Mär 1859 trat der Kranke in das Stadthospital zu Tiffis ein. Die Geschwulst hatte damals eine konische Form; die Basis derselben bildete das Stimbein, die Spitze lag zwischen den Augenbrauen und der herunterhängende Theil bedeckte $\frac{2}{3}$ der Nase. Die Grenzen der Basis bildete der äussere Rand der Augenbrauen, und von hier sich nach oben ausserbalb der Tubera frontalia erbebend, erstreckte sich die Geschwulst bis zum Band der Haare; dieser letzte Theil war ebenfalls etwas erlioben. Von der Basis verjüngte sich die Geschwulst allmälig bis zur Spitze, die bedeutend hervorsprang. Da die Gescliwulst keine genügende Stütze hatte, so bog sie sich herunter und bedeckte $\frac{2}{3}$ der Augenhöhlen und der Nase. An ihrer Spitze befanden sỉch die zwei künstlich hervorgebrachten Oeffnungen.

Die eingeführte Sonde drang bis auf 8 Zoll in die Geschwulst binein ohne dabei auf Knoclen zu stossen. Die Lider beider Augen waren stark ödematös geschwollen, von der Grösse eines Hübnereies und reichten beinabe bis zu den

Sulci naso-labiales herunter. Rechts war die Anschwellung bedeutender, wie man das in der Zeichnung selen kani. Die haut in der Umgegend der Geschwulst war leicht geröthet, anf der Geschwulst selbst dunkel violett, auf den unteren Lidern sclimntzig blass. Ueber der Geschwulst war die Haut unbeweghich nnd mit den darunterliegenden Theilen verwaclsen. Nach dem Druck mit dem Finger auf die Augenlider und die Umgegend der Geschwulst hinterblieb eine Jang anhaltende Grube. Beim Betasten der Stirngeschwulst füblte $\mathrm{man}^{\mathrm{n}}$ eine bedeutende Härte, jedoch war der obere Theil leicht verschiebbar, was auf eine innere Höhle hinwies. 


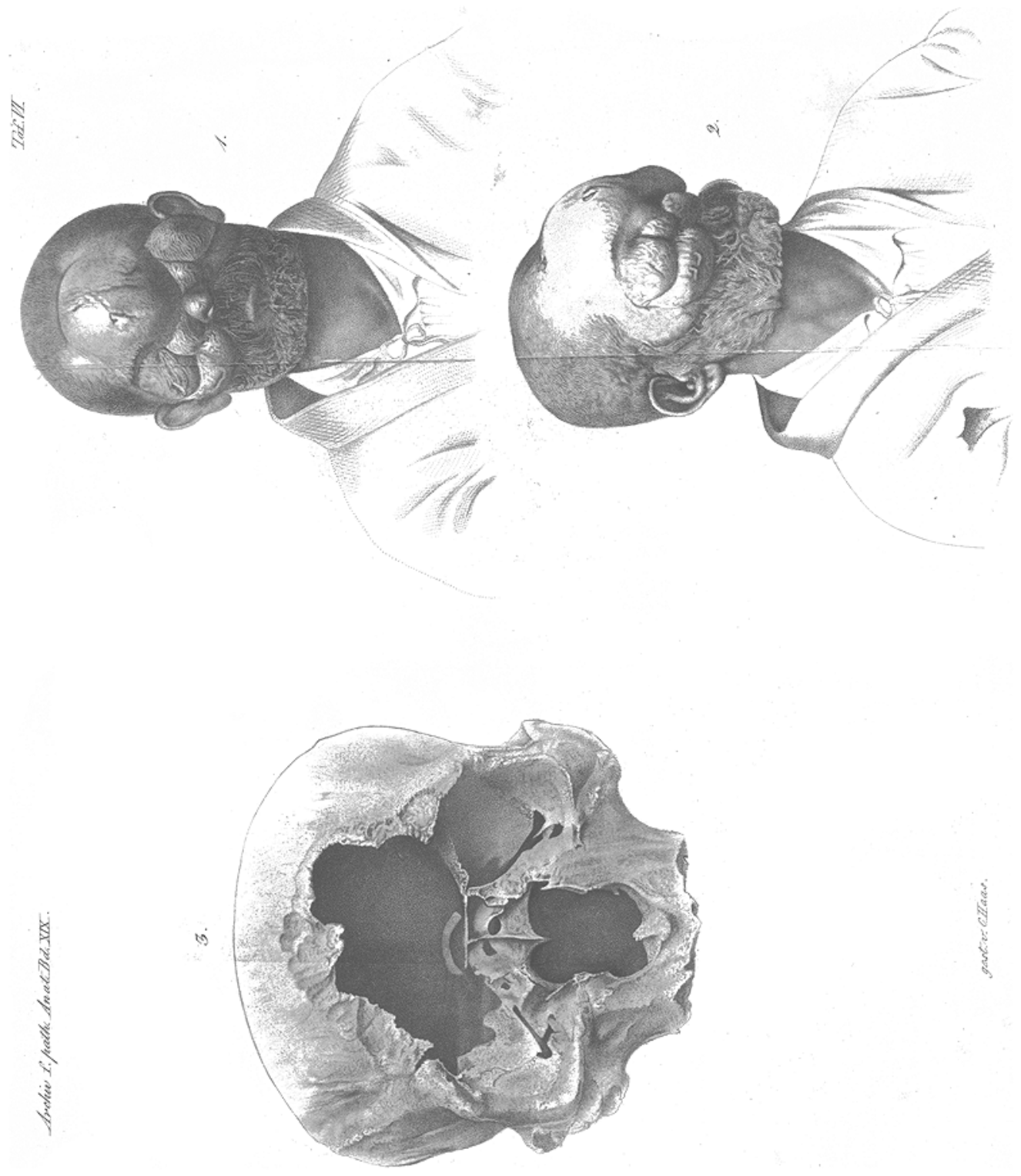


Aus den Einschnitten ergoss sich beständig eine reichliche, sehr ubbelriochesdo, dünne Flüssigkeit, in welcher man verönderte Blutcoagula und nekrotisirte Knochentheilcben constatiren konnte.

Den 1. April wurden die beiden Oeffnungen, um den Abfluss des Secrets zu erleichtern, durch einen Schnitt vereinigt. Bei der Untersuchung mit dem Finger erwies sich eine bedeutende und tiefe Höhle, deren Wände mit polypenartigen Auswüchsen von der Grösse einer Wallnuss besetzt waren; zwischen diesen Auswüchsen hatten sich kleine nekrotische Knochenstücke angesammelt. Auch bei dieser Untersuchung konnte man das Stimbein nicht erreichen, fand aber Gänge, die bis an die Augenhöblen reichten. Wälırend der Untersuchung bekam der Kranke leichte Convulsionen, stärker in den unteren Extremitäten, darauf folgte eine Olnnmacht. Die Schleimhaut des rechten Auges war leicht injicirt, die des. linken vollkornmen normal. Um sehen zu können, hebt der Kranke die Augenlider mit dem Finger hervor. Die Farbe und der Ausdrack des Gesichts waren so, wie man sie gewöhnlich bei Leuten beobachtet, die an einem Krèbsgeschwür leiden. Gehirnerscheinungen waren im Uebrigen niclıt zu constatiren. Der Kranke beschrieb seinen Zustand sehr deutlich und umständlich. Ebenfalls befanden sich die Organe der Brust - und Bauchlöhle in einem gesunden Zustande. Nach dem Eintritt ins Hospital verordnete man dem Kranken öfters Abwaschen des Geschwürs mit einer Solution von Chlorkalk, auf die Augenlider eine Solutio von Acetas aluminis (Burow).

2. April. Die Augenlider schwellen stärker an und röthen sich. Das Fieber vermehrt sicl. Keine Convulsionen.

4. April. Kopfsclimerzen, Unrulie, trockene Zunge; fieberhafter Zustand bedeutender, und darauf ein starker Schweiss: Potio River. und Decoct, gramin. $\bar{a} \bar{a}$ Unc. iij, Aqua laurocerasi Dr. i.

8. April. Der Kranke ist ohne Besinnung, sebr unruhig, phantasirt, schreit stark auf und macht unrubige Bewegungen; trockene Zunge, das Fieber ist beständig: Aquae oxymuriatic. Unc. $\beta$, Aqu. destillat. Unc, vi, alle zwei Stunden eiren Esslöffel voll. In diesem Zustande befand sich der Kranke bis zum 12ten Tage, worauf ein tiefes Coma eintrat.

14. April. Stilles Phantasiren, Subsultus tendinum, Convulsionen der oberen und unteren Extremitäten und des Únterkiefers. Ber Puls sehr schwach: Zinci acet. Gr. $\frac{1}{2}$, alle Stunden ein Pulver. Des Abends der Zustand noch schlechter; den 16 ten starb der Kranke.

Die Obduction wurde nach Verlauf von mehr als 48 Stunden nach dem Tode vorgenommen. Man bemerkte Folgendes: Allgemeine Abgezehrtheit des ganzen Körpers, schmutzig gelbe Farbe der Haut; Todtenflecke und Todtenstarre werden nicht beobachtet. Das Oedem der linken Lider und des unteren des rechten Auges war verscliwunden; die Lider stellten in Folge der früher dagewosenen Anschwellung cine Art vor Sack das. Das obere Lid des reclaten Auges und die Geschwulst sind etwas verkleinert.

Nachdem ein Ireuzschnitt durch die Geschwulst gemacht war, überzeugten wir uns, dass wir ein Carcinom vor uns hatten. Das krebsige Produkt erstreckte 
sich bis in die Augenböhle, besonders in die rechte und bis zur Fossa nasalis. In dem oberen Lide des rechten Auges sind ebenfalls krebsartige Ablagerungen. Die Höble der Geschwulst, die man schon während des Lebens constatirte, ist mit erweichten krebsartigen und nelrotischen Massen besetzt. An den Grenzen der Geschwulst ist das Periost vom Knochen abgelöst, scheint aber normal zu sein, In dem obcren Theile des Schı̈dels ist nichts Besonderes zu bemerken.

1. Die fibröse Hirnhant ist auf der rechten Hälfte mehr gespannt als auf der linken. Beim Durchschneiden derselben fliesst eine bedeutende Quantität dicker und stinkender Flüssigkeit aus. Eine eben solche Flüssigkeit bedeckt die innere Fläche der fibrösen Hirnhaut und die äussere der Pia mater. Nach Wegnahme der hellen flüssigen Masse sieht man, dass die innere Fläche der fibrösen Hirnhaut ihren Glanz verloren hat, stellenweise ist sie vascalarisirt und mit Exsudatmassen bedeckt, die mit derselben vollkommen fest zusanmenhängen. An einigen Stellen finden sich unter den Exsudaten schmutzig dunkelrothe Flecke als Folge früherer Blutergïsse. Dic Exsudate und Flecke sind besonders Läufig an demjenigen Theile, der den worderen Hirnlappen entspricht. Die Oberfläche der Pia mater ist mit Eiter bedeckt, der sich leicht durch den Wasserstrahl abspült; die Seitentheile sind ebenfalls mit diesem Eiter bedeckt, unten aber nur derjenige Theil, der dem vorderen Lappen entspricht. Beim Herunterziehen der Pia mater findet man, dass sich zwisclien dem Processus falciformis und dem hinteren Lappen der rechten Hemisphäre eine bedeutende Quantität eines gelben und dicken Ejters angesammelt hat.

Die Gefässe der Pia mater sind in ihrem Lumen vergrössert und mit Blut überfïltt, die Membran selbst verdickt, bärter und von Eiter durchdrungen.

In der rechten Hälfte des Gehirns sind zwei Abscesse etwas grösser als eine Wallnuss. Der eine liegt im vorderen Lappen über dem Tractus nervi olfactorii supra laminan cribrosam ossis ethmoidei; der andere im hinteren Lappen an der Innenfläche, da, wo sich die Ansammlung des Eiters befand. Der Inhalt der Abscesse und die Wände derselben bestelien aus einer weichen, fetzigen und necrotisirenden Masse. In der Umgebung der Abscesse zeigt die Hirnmasse diejenigen Veränderungen, wie sie nach Entzündungen des Gehirns beobachtet werden. In den anderen Theilen sind viele Blutpünktchen.

1I. Linke Hälfte. Nachdem die fibröse Haut abgenommen war, bemerkte man auf der inneren Seite derselben nicht die Veränderungen, die auf der rechten Hälfte zu finden waren. Die Pia mater, soweit sie den vorderen Lappen bedeckt, ist von Eiter durchdrungen. Im Lappen selbst in derselben Lage, wie auf der rechten Seite, befindet sich ein Abscess. Die Marksubstanz wie in der rechteri Hälfte. Der Plexus choroides mit Blut überfültt. Nach Herausnabme des Gehirns zeigt es sich, dass die fibröse Hirnhaut vorne, dem Sitze der Abscesse entsprechend, weich, leicht zerreissbar und von schmutzig grauer Farbe ist, jedoch im vollkommenen Zusammenhange. Auf der üusseren Seite der fiturösen Hirnhaut, da, wo sie die Fossa anterior et media bedeckt, sitzen vereinzelte krebsige Auswüchse, älınlich kleinen Warzen von der Grösse einer Erbse und darunter. Diese Auswïchse sind granulirt; ziemlich hart und von schmutzig rother Farbe; einige haben 
eine breite Basis, andere sind gestielt; einige sassen in Vertiefungen der Lamina anterior, andere in der Diploë. Zwischen den Vertiefungen bemerkt man einige Stellen, wo die innere Platte verdünnt, weich, halbdurchsichtig, wie glasartig, ähnlich einem Knorpel geworden ist. Unter diesen Stellen in der Diploë liegen krebsartige Massen. - 1857 machte ich Versuche über die Wirkung der Milchsäure auf Knochen. Ich legte kleine Kinochenstïcke in verdünnte Milchsäure, wo sie $1 \frac{1}{2}-$ 2 Wochen liegen blieben. Eine dünne schicht an den Rändern bekam ein knorpelartiges Aussehen, sie wurden durchsichtig, weich und elastisch. Fin älnnliches Aussehen hatte die Lamina externa cranii, wo sie die lirehsartigen Massen bedeckte.

Die hauptsächlichsten Veränderungen waren der Verlust der Partes horizontales, sowie der mittleren Theile der Pars coronalis ossis frontis und des Os ethmoides. Der besseren Untersuchung wegen wurde der Kopf macerirt und die weichen Theile vorsichtig entfernt; da erwies sich, dass der untere mittlere Theil ler Pars coronalis, der Nasen- und Orbital-Theil des Os frontis, das Os ethmoides, die Nasenknochen, ein Theil des linken kleinen Flïgels, die Mitte und der ganze rechte kleine Flägel des Proc. pterygoides des 0s splıcnoides, der obere Theil des Nasenfortsatzes des Unterkiefers fehlen, wie man das auch an der Zeichnung sehen kann. Der Rand des übriggebliebenen Stirnknochens ist von allen Seiten unegal, ausgebröckelt, wie zerfressen. Die Lamina externa ad lineas semilunares batte ihre Glätte verloren, ist porös und ungleich. Die Lamina ad lineam mediam ist ganz normal. Die vollständige Beschreibung der Ränder ist unnütz, man kann dieselbe aus der Zeichnung gut ersehen. Eine mikroskopische Untersuchung der Geschwulst ist niclıt gemacht worden.

Der rechte Pleurasack ist schon von früher her verwachsen; die rechte Lunge ödematös, die linke frei und enthält wenig Blut; das Herz fettig; in der rechten Hälfte desselben sind kleine weiche Coagula. Dic Leber muskatartig, etwas vergrössert, die Galle dick und dunkelgrün; die Milz $2 \frac{1}{2} \mathrm{mal}$ grösser als gewölunlich und besonders in der Lănge, die Farbe des Durchsclunitts gleicht ausgewăssertem Fleische; die Nieren normal.

Dieser Full eines Knochenkrebses ist deshalb beachtungswerth, weil er in Folge eines Trauma entstand und trotz der bedentenden Zerstörung der angrenzenden Theile die Augäpfel unbeschädigt liess.

Es ist zu bedauern, dass wegen des Mangels eines Mikroskops niclt festgestelit werden konnte, welch' eine Abart des Krebses wir im gegebenen Falle vor uns hatten. Jedoch liessen die äusseren Eigenschaften, die schnelle Entwicklung der Geschwulst in der letzten Zeit, die starken Schmerzen und die Art der Krankheit schliessen, dass wir es mit einem Medullarcarcinom, das in der Diploë seinen Anfang nahm, zil thun latten. 